\section{La importancia de reducir la carga viral para disminuir el riesgo de contagio por COVID-19}

\author{
The importance of reducing the viral load \\ to diminish the risk of COVID-19 spread \\ Dr. Jesús Cuenca-Pardo,* Dr. Guillermo Ramos-Gallardo,* \\ Dra. Estela Vélez-Benítez, * Dr. Carlos de J Álvarez-Díaz, \\ Dr. Javier Bucio-Duarte,* Dr. Rufino Iribarren-Moreno,* \\ Dr. David Rodríguez-Marín, ${ }^{\S}$ Dra. Livia Contreras-Bulnes*
}

Palabras clave: SARS-CoV-2, COVID-19, carga viral, contagio, cuidados profilácticos, mascarillas faciales.

Keywords: SARS-CoV-2, COVID-19, viral load, contagion, prophylactic care, face masks.

\footnotetext{
* Integrante del Comité de Seguridad de la Asociación Mexicana de Cirugía Plástica, Estética y Reconstructiva, A.C.

¥ Asesor. AMCPER

§ Ingeniería Biomédica. Instituto Nacional de las Mujeres.
}

Recibido:

17 septiembre 2020 Aceptado para publicar: 20 septiembre 2020

\section{RESUMEN}

Realizamos una revisión sistemática sobre la importancia de disminuir la carga viral, como una estrategia para reducir el riesgo de contagio o para disminuir la severidad de la enfermedad. Seleccionamos 113 publicaciones y analizamos los conceptos teóricos y las recomendaciones las realizamos con la mejor evidencia médica disponible. La carga viral está relacionada con la tasa de ataque y severidad del COVID-19. Se ha reconocido que la producción de aerosoles es la principal fuente de contagio entre el personal sanitario. El riesgo de contagio es más alto en espacios cerrados y mal ventilados donde se convive con varias personas por mucho tiempo sin el debido distanciamiento y sin protección. La tasa de contagio es mayor al $80 \%$ y la mortalidad es muy alta. Otra fuente de contagio alto se da entre el personal sanitario que tienen que atender pacientes COVID por largos periodos de tiempo, y aspiran sus secreciones respiratorias sin contar con el equipo de protección adecuado. Los cirujanos y otros profesionales tienen que atender al público: personas desconocidas que pueden ser portadoras del virus, por lo que están expuestos al contagio. Los principales cuidados preventivos que ayudarán a disminuir la carga viral son: el uso generalizado de mascarillas, protección ocular, distanciamiento, higiene de las manos y desinfección del ambiente. Aunque faltan evidencias de su efectividad, estos cuidados deben aplicarse por precaución y deben ser obligatorios y universales.

\section{ABSTRACT}

We carried out a systematic review on the importance of reducing viral load, as a strategy to reduce the risk of infection or to diminish the severity of the disease. We selected 113 publications and analyzed the theoretical concepts and recommendations we made with the best medical evidence available. Viral load is related to the attack rate and severity of COVID 19. It has been recognized that the production of aerosols is the main source of contagion among health personnel. The risk of contagion is higher in closed and poorly ventilated spaces, where people stay with several individuals for a long time, without due distance and without protection. The contagion rate is higher than $80 \%$ and there is a very high mortality. Another source of super spread occurs among health personnel who must care for COVID patients for long periods of time, and inhale their respiratory secretions, without having appropriate protective equipment. Surgeons and other professionals must attend the public: unknown people who may be carriers of the virus; therefore, are exposed to contagion. The main preventive protection that will help us reduce the viral load is: the widespread use of masks, eye protection, distancing, hand hygiene and sanitation of the environment. Even though there is a lack of evidence regarding their effectiveness, these should be used for precaution and must be compulsory and universal.

Citar como: Cuenca-Pardo J, Ramos-Gallardo G, Vélez-Benítez E, Álvarez-Díaz CJ, Bucio-Duarte J, IribarrenMoreno R et al. La importancia de reducir la carga viral para disminuir el riesgo de contagio por COVID-19. Cir Plast. 2020; 30 (2): 78-93. https://dx.doi.org/10.35366/97674 


\section{OBJETIVO}

T a pandemia de COVID-19 permanecerá $\perp$ por largo tiempo. A pesar del riesgo, hemos regresado a nuestras actividades, lo cual debe hacerse en una forma responsable y segura. Algunas acciones prácticas sin los cuidados correspondientes aumentarán el riesgo de contagio. El objetivo del presente trabajo es elaborar recomendaciones de seguridad para los cirujanos plásticos que también puedan ser empleadas por otros profesionales que tienen que atender al público en general y están expuestos al contagio por COVID-19, con el fin de reducir la carga viral $y$, al hacerlo, disminuir el riesgo de contagio o adquirir la enfermedad, sea en su forma leve o asintomática. Las recomendaciones están basadas en la mejor evidencia médica disponible y bajo el principio de precaución.

\section{METODOLOGÍA}

Realizamos una revisión sistemática en español e inglés en los sitios de información: PubMed, Embase, Cochrane, Medline, Fisterra, Medigraphic y Google Académico. Las palabras clave en español que utilizamos fueron: SARS-CoV-2, carga viral COVID-19, contagio, cuidados profilácticos, mascarillas faciales, respiradores faciales, distanciamiento, protección ocular, equipo de protección personal, lavado de manos y desinfección del ambiente. Elaboramos preguntas básicas relacionadas con el tema, buscamos la mejor evidencia médica disponible para contestar cada pregunta y realizamos un consenso de un grupo de cirujanos con experiencia en el tema. Con los datos obtenidos elaboramos recomendaciones preventivas para el personal de salud y para los pacientes y elaboramos unas infografías como guías rápidas y sencillas, pero con la información suficiente que permita al cirujano disminuir la carga viral y reducir el riesgo de contagio.

\section{HALLAZGOS}

En PubMed encontramos 6,334 publicaciones sobre carga viral y COVID-19 en Google Académico: 23,700. Seleccionamos 113 artículos que dieran contestación a las preguntas que formulamos. Encontramos tres metaanálisis (nivel de evidencia I), cuatro revisiones sistemáticas (nivel de evidencia I y II), dos estudios de cohorte prospectiva (nivel de evidencia II), dos reportes de casos (nivel de evidencia IV), tres guías o manuales (nivel de evidencia IV) y 99 revisiones simples u opiniones (nivel de evidencia V). Una de las publicaciones encontradas fue realizada por el grupo de Cochrane.

\section{¿Qué es la carga viral y para qué sirve cuantificarla?}

A la cantidad de partículas virales en el plasma, secreciones respiratorias o excretas del paciente se le ha denominado carga viral. Se calcula por estimación de la cantidad de partículas virales en los fluidos corporales. ${ }^{1}$ La cuantificación de la carga viral es de gran utilidad para evaluar la severidad de la infección, pronosticar la evolución de las infecciones virales y sus recaídas. Ayuda a valorar el resultado del tratamiento, determinar si la carga aumenta o permanece, o si el tratamiento no ha sido eficaz. ${ }^{2}$ La cuantificación se puede realizar por diferentes medios. El más simple y accesible es por reacción en cadena de la polimerasa (PCR) cuantitativo, que permite detectar cargas virales mínimas en la sangre y es más sensible que el PCR cualitativo tomado de exudado en la faringe. El examen de PCR cualitativa detecta por arriba de 200 copias de virus por mililitro; la cuantitativa alcanza a detectar 20 copias de virus por mililitro; por ende, es 10 veces más sensible. ${ }^{1-3}$

\section{¿Qué relación existe entre la carga viral y la severidad de la COVID-19?}

Hay varias evidencias de que el SARS-CoV-2 puede ser fácilmente transmisible en una etapa temprana de la infección y en pacientes asintomáticos, lo que sugiere una alta carga viral en esta etapa. Los casos asintomáticos son más frecuentes en niños. ${ }^{4-6}$

En un estudio se realizó la determinación de carga viral en esputo y en heces fecales en 96 pacientes, donde la diseminación viral máxima la encontraron de 10 a 12 días y el tiempo de duración fue de 18 días. Los casos con mayor severidad de la enfermedad tuvieron mayor carga viral. En muestras del tracto respiratorio alto, se encontró mayor carga en 
las etapas iniciales de la enfermedad. En las tomas del tracto bajo, las muestras fueron altas hasta 14 días. En heces fecales el tiempo de duración es mayor que en las vías respiratorias. Las heces pueden ser un vector de contagio importante; por lo que se destaca la importancia del manejo de las heces para evitar contagio. En el plasma de los pacientes se encontró el virus hasta en el 59\% de los casos. La carga fue alta aún después de ya no encontrar el virus en las vías respiratorias. Rara vez se encontró el virus en orina. La aplicación de esteroides estuvo relacionada con un mayor tiempo de presencia viral. El tiempo de duración es mayor en hombres que en mujeres y podría estar relacionado el efecto de las hormonas. En pacientes mayores de 60 años, la duración del virus es mayor, probablemente por un déficit inmunitario propio de la edad y por mayores niveles de enzima convertidora de angiotensina 2 en los alveolos, que se supone es un receptor de los diferentes coronavirus. ${ }^{7}$

En estudios recientes, se encontró que las cargas virales en casos severos eran hasta 60 veces mayores que en casos leves. ${ }^{2}$ En el grupo de individuos asintomáticos, el tiempo de contagio promedio fue de 19 días, menor que el grupo sintomático $(p=0.02)$. La IgG de los asintomáticos fue de 3.4 vs 20.5 de los sintomáticos $(p=0.005)$. Las citoquinas fueron menores en los asintomáticos. ${ }^{8}$

Se ha identificado el virus durante el curso de la infección en muestras de vías respiratorias uno a dos días antes de los síntomas y persistir hasta dos semanas en casos severos. ${ }^{9}$ También se ha detectado desprendimiento de ARN viral en las heces, exudado faríngeo, sangre, plasma, saliva y orina, desde cinco días después del inicio de los síntomas hasta cuatro a cinco semanas., ${ }^{7,9-13}$

La eliminación del $A R N$ viral no equivale a la infectividad, sino al tiempo que las personas afectadas continúan desprendiendo partículas virales. ${ }^{2}$

\section{¿Cómo nos contagiamos?}

Una fuente de contagio de COVID-19 es por la convivencia cercana a un paciente sintomático y hacerlo sin los debidos cuidados; no obstante, la causa más frecuente son las personas asintomáticas o presintomáticas: al no ser ostensible la enfermedad, se tiende a un mayor descuido con un mayor riesgo. ${ }^{5,13-19}$

No se sabe con certeza cuántos virus se necesitan para que alguien se infecte. Estudios recientes ofrecen algunas pistas: en una investigación cuyos resultados fueron publicados recientemente en la revista Nature, los científicos afirman que no pudieron cultivar el coronavirus vivo si el hisopo o esputo de un paciente contenía menos de un millón de copias de ARN viral, por lo que se requiere de una cantidad mayor para la infectividad; sin embargo, el virus en condiciones adecuadas de ambiente y huésped susceptible es altamente contagioso. El 10\% de los casos positivos contagian al 80\% de los nuevos casos; es decir, un paciente contagia a ocho personas. La tasa de ataque es muy variable y aún está por definirse, ya que algunos enfermos contagian a muchos, mientras que otros no contagian. . $^{8-11}$

La proporción de asintomáticos es una cantidad útil para medir la verdadera carga de la enfermedad e interpretar mejor las estimaciones del potencial de transmisión. ${ }^{1}$ Esta proporción varía ampliamente entre las enfermedades infecciosas, desde el $8 \%$ para el sarampión, $32 \%$ para las infecciones por coronavirus, hasta el $90-95 \%$ para la poliomielitis. ${ }^{5-7}$ Se calcula que el porcentaje de individuos asintomáticos para SARS-CoV-2 debe ser mayor al 80\%. ${ }^{9-12}$

Se reporta que la transmisión puede ser directa al estar en contacto estrecho, menos de 1 metro con un paciente infectado productor de pequeñas gotas respiratorias con alta carga viral; en estas circunstancias, las partículas son aspiradas depositándose en las mucosas. Otro medio es la transmisión indirecta por fómites: las gotas expulsadas por los pacientes se depositan sobre las superficies u objetos, desde horas hasta días, dependiendo del material. Cuando una persona toca estos fómites y después se toca la cara corre el riesgo de infectarse. Otro medio de transmisión es la aérea. Algunos procedimientos pueden generar aerosoles con microgotas con diámetro $<5$ $\mu \mathrm{m}$ que pueden permanecer en el aire durante periodos prolongados y llegar a personas que se encuentren a más de un metro de distancia. Algunos procedimientos generadores de aerosoles son: administración de un fármaco por nebulización, intubación endotraqueal, 
aspiración abierta, broncoscopia, ventilación manual antes de la intubación, giro del paciente a decúbito prono, desconexión del paciente de un ventilador, ventilación no invasiva con presión positiva, manejo de traqueotomía, reanimación cardiopulmonar, técnicas de inducción de esputos. ${ }^{19-25}$

\section{Humo por procedimientos quirúrgicos}

Los cirujanos y el personal del quirófano están expuestos constantemente al humo generado por la destrucción térmica de los tejidos. El humo generado representa un peligro químico y biológico, $1 \mathrm{~g}$ de tejido fulgurado equivale a seis cigarros. ${ }^{26}$ La abdominoplastia es el procedimiento de cirugía plástica que más partículas genera, se pueden producir hasta 3,900 partículas $/ \mathrm{cm}^{3}$, mientras que en un reemplazo de cadera se producen $400 / \mathrm{cm}^{3}$; también se produce una gran cantidad durante la cirugía de reducción mamaria. ${ }^{27}$ En el humo quirúrgico, se han encontrado los virus de la hepatitis y del $\mathrm{VIH} ; 28,29$ el tamaño de las partículas en el humo oscilan de 0.05 a más de 25 micras. El virus de la hepatitis B mide 0.042 micras, ${ }^{27}$ el del VIH de 0.1 a 0.12 micras $^{27}$ y el del coronavirus mide 0.1 a 0.16 micras. ${ }^{30}$ Las mascarillas faciales filtran partículas de más de 5 micras, siendo ineficaces incluso usándose correctamente. ${ }^{29,31}$ El virus del SARS-CoV-2 podría estar presente en el humo quirúrgico y trasmitirse por inhalación. No existen casos documentados a través de este medio de transmisión. El personal de quirófano debe tomar en consideración esta posibilidad y estar debidamente protegido del efecto del humo y evitar la formación de aerosoles, disminuyendo el uso de los dispositivos generadores de energía. ${ }^{30-32}$

\section{¿Cuál es el medio de mayor transmisión de la infección por SARS-CoV-2?}

Muchos investigadores aseguran que es poco común contagiarse de coronavirus al entrar en contacto con una superficie contaminada, también durante un encuentro fugaz con personas que estén infectadas. Se ha identificado el contacto con microgotas respiratorias de un paciente y su efecto aerosol como el principal modo de transmisión de COVID-19. Las gotas menores de 5 micras pueden permanecer en el aire durante mucho tiempo y ser aspiradas y depositadas en los alveolos pulmonares, mientras que las gotas grandes caen al suelo y se secan rápidamente. Sistemas de mala ventilación en espacios cerrados hacen que los virus suspendidos en el aire recirculen, aumentando el riesgo de contagio. Las circunstancias más comunes para los contagios serían los encuentros cara a cara y las interacciones entre personas durante periodos prolongados. ${ }^{19-22}$

\section{¿Qué es un supercontagio?}

La tasa de ataque del COVID es más alta en espacios cerrados y mal ventilados donde se convive por mucho tiempo con varias personas sin el debido distanciamiento y sin protección. La mayoría de las veces se ignora que alguna de ellas ya está enferma de COVID, además, son lugares donde la gente habla en voz alta o canta. Se ha estimado que hablar en voz alta un minuto genera al menos mil gotitas con partículas virales, que podrían quedarse hasta ocho minutos en el aire. A este conjunto de condiciones se le ha denominado supercontagio y se ha presentado en integrantes de coros musicales en iglesias, en personas que acuden a restaurantes o viajan en autobús o participan en fiestas, con una tasa de contagio mayor del $80 \%$ y una mortalidad muy alta, mientras que el porcentaje de contagio es muy bajo, del 4 al $19 \%$, en familiares de pacientes COVID que han seguido el aislamiento y cuidados de protección personal durante la enfermedad. ${ }^{19-22}$

Otra fuente de supercontagio se da con el personal sanitario, que durante largos periodos de tiempo tienen que atender pacientes $\mathrm{CO}$ VID, aspirar sus secreciones respiratorias y no cuentan con equipo adecuado de protección personal. La tasa de ataque del COVID-19 entre el personal de salud fue muy alta al inicio de la pandemia; sin embargo, al mejorar los cuidados y el uso exhaustivo del equipo de protección personal (EPP), los casos se redujeron considerablemente. ${ }^{20-22,33}$

\section{¿Cuál es el riesgo de contagio en el personal sanitario?}

El personal sanitario que realiza su trabajo sin una adecuada protección tiene tres veces más 
riesgo de contagio, aumenta hasta cinco veces más cuando es personal de primera línea que atiende pacientes con COVID. El riesgo también aumenta con personal de color, asiático, etnias minoritarias o comorbilidades. ${ }^{33}$

\section{¿Cuándo debemos considerar que una persona es un caso sospechoso?}

Todos los pacientes deben ser considerados como casos sospechosos hasta que se descarte la enfermedad. Deberán ser tratados con protocolos de seguridad extremos. Hay muchos pacientes asintomáticos o presintomáticos que sin saberlo están diseminando el virus y exponiendo a otros pacientes $y$ al personal sanitario al riesgo de contagio. ${ }^{19-22,34-38}$

\section{¿Cómo podemos reducir la carga viral?}

Durante la pandemia, las actividades que implican una relación interpersonal requieren de normas efectivas para evitar el contagio de $\mathrm{CO}$ VID-19. Diferentes organizaciones sanitarias y el consenso de varios especialistas han emitido protocolos de actuación con la finalidad de disminuir los contagios. Se puede continuar con las actividades laborales si se implementan distintos mecanismos para evitar contagios masivos en la población, estableciendo estrategias para la contención viral, como: exigencia en el uso de máscaras faciales, implementación de buenos sistemas de ventilación, mantener ventanas abiertas, desinfección de las salas de trabajo por medios físicos o químicos, reducción de reuniones en espacios cerrados, limitar el uso del transporte público y ascensores, prohibición de abrazos, apretones de manos y golpes de puño, usar tabiques de plástico entre escritorios, mantener la distancia entre los trabajadores al menos 1.8 metros y realización de pruebas seriadas al personal. ${ }^{39-41}$

\section{¿Cuál es la importancia del uso de mascarillas faciales, distanciamiento y protección ocular para disminuir los contagios?}

El uso generalizado de mascarillas por parte de la población general puede servir para reducir la transmisión comunitaria del coronavirus, ya que se reduce la excreción de gotas respiratorias de individuos infectados que aún no han desarrollado síntomas o que permanecen asintomáticos. El uso de mascarillas en la comunidad está indicado principalmente cuando se acude a lugares con mucha gente, espacios cerrados o cuando se utiliza el transporte público. El uso de mascarillas en la comunidad se debe considerar como una medida complementaria y no como reemplazo de las demás medidas preventivas establecidas, como la higiene de manos. ${ }^{42,43}$

El uso de mascarillas faciales reduce el inóculo del virus, lo que provoca una infección más leve y asintomática. Es de utilidad en población que tiene que permanecer en entornos cerrados (por ejemplo cruceros, oficinas, centros de trabajo). Las infecciones asintomáticas pueden ser perjudiciales para la propagación, pero en realidad podrían ser beneficiosas si conducen a mayores tasas de una exposición controlada sin las consecuencias inaceptables de una enfermedad grave, lo que podría conducir a una mayor inmunidad en la comunidad con una más lenta diseminación. Algunas mascarillas tienen un efecto de contención viral o disminuyen su flujo con una menor carga del virus, sin alcanzar la DL50. Existe un marcado incremento de infección leve o asintomática en poblaciones que han optado por el uso generalizado de las mascarillas faciales. ${ }^{44}$

Durante la respiración, tos o estornudo de pacientes, son expelidas partículas de diferentes tamaños. Las que miden entre 60 a 100 micras caen al piso. Las gotas respiratorias más pequeñas forman aerosoles que contienen grandes cantidades de partículas menores a 5 micras; pueden alcanzar distancias de siete a ocho metros y permanecer en el aire durante mucho tiempo. Al ser tan pequeñas, pueden ser aspiradas y depositarse en los alveolos pulmonares, produciendo la enfermedad. Esta forma explica uno de los mecanismos de supercontagio. El uso de mascarillas quirúrgicas no es suficiente para contener al virus, se requiere el uso de respiradores con filtro de contención viral. Los respiradores pueden contener hasta el 97\% de partículas de aerosol y reducir el riesgo de contagio. Para evitar el desabasto, la Organización Mundial de la Salud y los Centros para el Control y la Prevención de Enfermedades de 
los Estados Unidos (CDC) recomiendan que el público lleve mascarillas de tela y dejar para uso exclusivo del personal sanitario las mascarillas quirúrgicas y las N95 o similares. ${ }^{45-53}$

En la actual pandemia de COVID, se han emitido consejos contradictorios sobre los cuidados para prevenir el contagio; las mayores controversias son con el uso de las mascarillas por la comunidad y el distanciamiento. Las mascarillas se han utilizado por décadas para la prevención de infecciones, ahora enfrentan desafíos en medio de la escasez y la ignorancia. Las recomendaciones deben basarse en la mejor evidencia disponible, muchas de ellas provienen de otras infecciones virales respiratorias, pero no se dispone de una revisión exhaustiva de información sobre SARS-CoV-2. ${ }^{54-72}$

Mascarillas quirúrgicas. Una mascarilla quirúrgica se define como un dispositivo desechable que tiene la intención de crear una barrera física entre la boca y nariz del usuario y los posibles contaminantes en el entorno inmediato. ${ }^{1}$ Estos dispositivos tienen la intención de proteger al usuario contra salpicaduras de fluidos corporales que se generan durante procedimientos de atención médica y no brindan ningún tipo de protección respiratoria, dado que no generan un sello en el rostro del usuario. ${ }^{67-73}$

Estos dispositivos están regulados por la Administración de Alimentos y Medicamentos (FDA, por sus siglas en inglés) y por los diferentes estándares ASTM (F2100, F2101, F2299, F1862) en los Estados Unidos de Norteamérica. Esta normatividad determina la calidad y eficiencia de las mascarillas y requieren evaluaciones de desempeño de los siguientes parámetros: resistencia a fluidos, eficiencia de filtración bacteriana y de partículas, inflamabilidad y biocompatibilidad. La eficiencia de filtración bacteriana se realiza con un aerosol de prueba de aproximadamente $3.0 \pm 0.3 \mu \mathrm{m}$ y se confunde comúnmente con la eficiencia de filtración de partículas con la que se aprueban equipos de protección respiratoria. ${ }^{74}$

Mascarillas de tela. Para evitar el desabasto de las mascarillas quirúrgicas o la N95, la CDC (Centers of Disease Control and Prevention of United States of America) y la OMS han recomendado las mascarillas de tela para que sean usadas por el público en general. La mascarilla de tela atrapa las gotitas que miden entre 5 y 10 micras, que son liberadas cuando la persona que la usa habla, tose, o estornuda. Cuando su uso es generalizado en lugares públicos, pueden ayudar a reducir la trasmisión del virus. Los países que han aceptado su uso asociado a otras medidas, como pruebas de detección, aislamiento y distanciamiento físico temprano en el curso de la pandemia han tenido éxito en reducir la trasmisión del virus. Pueden fabricarse de materiales comunes, como sábanas de algodón con hilado apretado. Es fácil encontrar instrucciones en Internet para su elaboración; las mascarillas de tela deben tener varias capas. La CDC en su sitio WEB incluye instrucciones para hacer mascarillas de tela. ${ }^{42-45,65,66}$

Equipos de protección respiratoria (respiradores). Se define como respirador un equipo de protección personal que purifica o suministra aire para proteger las vías respiratorias del usuario contra contaminantes que se encuentran en el medio ambiente laboral. Los respiradores se pueden clasificar en: purificadores de aire de presión negativa o positiva y suministradores de aire con sistemas de línea de presión positiva o negativa. Estos dispositivos están diseñados para proporcionar protección contra cualquier contaminante disperso en el medio ambiente, siempre y cuando se hayan seleccionado de acuerdo con el peligro presente en el medio ambiente y que el usuario lo utilice de forma correcta y consistentemente durante todo el tiempo que permanezca en el lugar de trabajo. ${ }^{67-78}$

Las autoridades sanitarias de todo el mundo sugieren el uso de respiradores N95 o sus equivalentes para profesionales de cuidados de la salud que están en contacto con personas confirmadas con el virus SARS-CoV-2 (COVID-19), especialmente en aquellos procedimientos en donde se propicia la generación de aerosoles. Se ha recomendado desechar los respiradores una vez terminando el tiempo de vida de los mismos, normalmente una jornada laboral. ${ }^{65-78}$

En los Estados Unidos de Norteamérica, el Instituto Nacional de Seguridad y Salud Ocupacional ( $\mathrm{NIOSH}$, por sus siglas en inglés), a través del estándar 42 CFR 84, estableció los lineamientos para la aprobación de respiradores. Dentro de dicho estándar, NIOSH clasifica respiradores para partículas en diferentes clases de 
acuerdo al tipo de medio filtrante y la eficiencia de filtración de respiradores (Tablas 1 y 2). 67-78

Los equipos de protección respiratoria pueden ser descontaminados por algunos métodos aprobados por la FDA. Esta autorización es válida solamente durante la declaratoria de emergencia sanitaria. Para que un método de descontaminación pueda ser aprobado por la FDA, se requiere que cumpla con las siguientes condiciones: ${ }^{78}$

- Inactivar de forma efectiva el virus SARSCoV-2.

- No dañar el medio filtrante o algún elemento del respirador (clip nasal, ligas de ajuste).

- No dañar el ajuste que brinda un respirador desechable.

- Que el método seleccionado no represente un riesgo para el usuario de respiradores.

Mascarillas N95. Son un tipo de respirador que ofrece más protección que una mascarilla quirúrgica porque puede filtrar tanto las partículas grandes como las pequeñas. Como su nombre lo indica, la mascarilla está diseñada para bloquear el 95\% de las partículas pequeñas. Algunas mascarillas N95 tienen válvulas que hacen que sea más fácil respirar a través de ellas, ya que la válvula libera aire no filtrado. Este tipo de mascarilla no evita que la persona que la lleva trasmita el virus. Por esta razón, algunos lugares prohíben usarlas. $\mathrm{Al}$ igual que las mascarillas quirúrgicas, la intención es que las N95 sean desechables, pero los investigadores están haciendo pruebas para encontrar maneras de desinfectar las mascarillas para que se puedan volver a usar. ${ }^{65,66}$

En un metaanálisis encontraron que la transmisión de virus fue menor cuando el distanciamiento físico era mayor a 1 metro; el riesgo disminuye 2.02 veces por cada metro extra de distancia $(p=0.041)$. Las mascarillas NK95 o similares reducen el riesgo de infección en un $14.3 \%$ comparadas con las mascarillas quirúrgicas $(p=0.09)$. La protección ocular también estuvo asociada con menos infección (10.6\%); se necesitan ensayos aleatorios más sólidos. En vista de las pautas inconsistentes de varias organizaciones basadas en información limitada, los hallazgos proporcionan algunas aclaraciones. ${ }^{65,66}$

\section{¿Cuál es la importancia de la higiene de las manos para prevenir el COVID-19?}

El virus SARS-CoV-2 es un virus encapsulado, con una membrana formada por lípidos y glucoproteínas. La capa externa les permite identificar y unirse a los puntos receptores de la membrana de la célula huésped, para fusionarse con ella y facilitar la entrada en la célula, donde se reproducirá. Los virus encapsulados son menos estables y muy susceptibles a la acción del jabón. ${ }^{53-66,79-85}$

La higiene de las manos se considera uno de los cuidados más efectivos para evitar la propagación de gérmenes y para prevenir el contagio por COVID-19, especialmente después de haber estado en espacios o medios de transporte públicos y haber tocado personas y/o superficies u objetos, o después de sonarse la nariz, toser o estornudar. Organismos como la OMS, Organización Panamericana de la salud (OPS) y la CDC recomiendan realizar un lavado de manos frecuente con agua y jabón, o, si esto no es posible, utilizar un desinfectante de manos a base de alcohol. ${ }^{53-66,79-85}$

\begin{tabular}{cccc}
\multicolumn{5}{c}{ Tabla 1: Clasificación de los respiradores de acuerdo al porcentaje } \\
de filtración y al tipo de partículas (NIOSH).
\end{tabular}




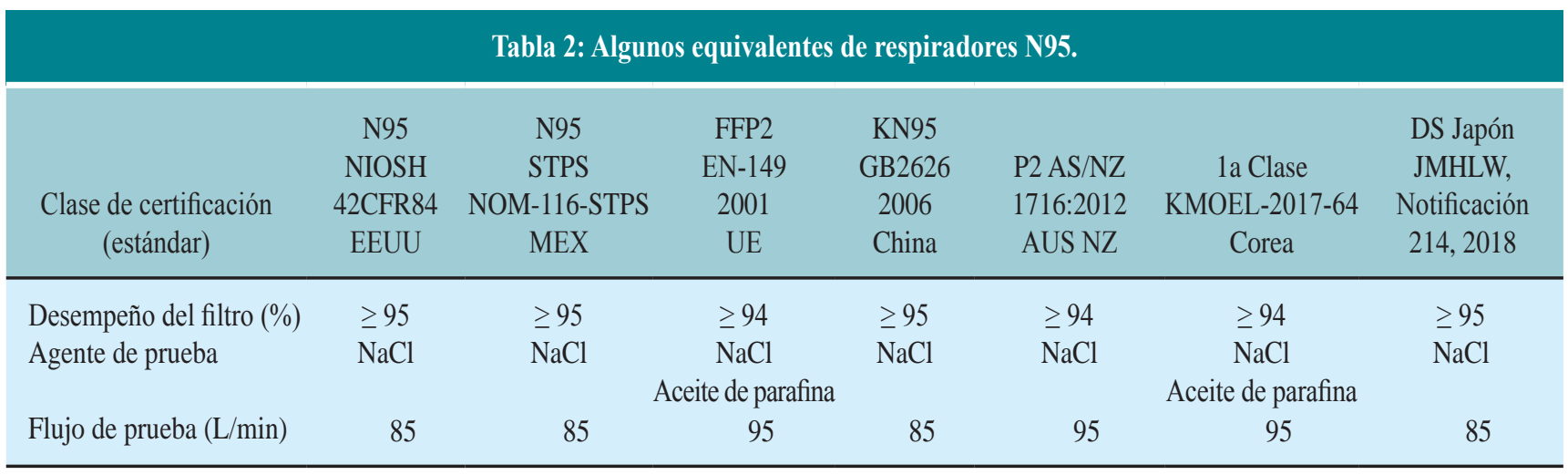

Usar jabón para lavarse las manos es más efectivo que usar agua sola porque los tensioactivos del jabón eliminan la suciedad y los microorganismos de la piel. Se considera además que las personas tienden a frotarse las manos más a fondo cuando usan jabón, lo que elimina los gérmenes. Para el lavado de manos se debe usar agua corriente limpia, ya que pueden volver a contaminarse si usamos agua estancada o reciclada. La CDC no recomienda el uso de jabones con germicidas, ya que no se obtiene mayor beneficio. ${ }^{53-66,79-85}$

El tratamiento higiénico de las manos con antisépticos o desinfectantes a base de alcohol a una concentración del 60 al 85\% brinda un beneficio adicional al lavado con agua corriente y jabón y puede ser de gran utilidad en las situaciones donde no exista acceso al agua corriente y jabón. Estos productos con alcohol pueden reducir rápidamente la cantidad de bacterias, hongos, levaduras, micobacterias y virus. Es importante tener en cuenta que si las manos están sucias o con grasa, deberán lavarse con agua y jabón antes de usar el antiséptico, ya que la suciedad puede reducir significativamente la acción del producto. ${ }^{53-66,79-85}$

\section{¿Cuál es la importancia de la limpieza y desinfección de espacios públicos?}

La limpieza y desinfección son parte importante de la reapertura de los espacios públicos y requiere una planificación meticulosa. La limpieza frecuente con agua y jabón reducirá la cantidad de virus que haya sobre las superficies y objetos que suelen tocar las personas, la desinfección ayudará a su eliminación. Estos cuidados disminuyen el riesgo de exposición. Los virus que se encuentran sobre superficies y objetos mueren de forma natural al cabo de horas o días; el calor, ventilación y luz solar reducen considerablemente el tiempo de supervivencia. ${ }^{53-66,79-85}$

Se recomienda evaluar el lugar de trabajo, escuela, casa o empresa para determinar qué tipos de superficie y materiales están presentes en esa área. La mayoría de las superficies y objetos sólo necesitarán una limpieza normal de rutina. Las superficies y objetos que se tocan con frecuencia, como los interruptores de luz y las manijas de las puertas, se deberán limpiar y después desinfectar para reducir aún más la presencia de gérmenes sobre superficies y objetos. Si su lugar de trabajo, escuela o empresa ha estado desocupada por siete días o más, sólo será necesario realizar una limpieza normal de rutina para reabrir el área. Esto se debe a que el virus que causa el COVID-19 no ha demostrado sobrevivir en superficies más de este tiempo. ${ }^{53-66,79-85}$

Los desinfectantes contribuyen a eliminar los gérmenes de las superficies, no sustituyen al jabón. Si hay poca existencia de desinfectantes se pueden usar $1 / 3$ de taza de blanqueador con cloro diluido en 1 galón de agua, o soluciones con un $70 \%$ de alcohol. Las soluciones de blanqueador con cloro serán efectivas para desinfectar hasta por 24 horas. Almacene y use los desinfectantes de manera responsable y adecuada según lo indicado en la etiqueta. No malgaste ni acumule desinfectantes $u$ otros suministros, esto puede provocar la escasez de productos que otras personas necesitan usar en situaciones críticas. No mezcle blanqueador 
con cloro con otros productos de limpieza y desinfección, hacerlo puede provocar vapores muy peligrosos. Mantenga todos los desinfectantes fuera del alcance de los niños. ${ }^{53-66,79-85}$

Algunos artículos contaminados (fómites) pueden ser cambiados de lugar o eliminados para reducir la manipulación o contacto. Los materiales blandos y porosos, como las alfombras y asientos, pueden quitarse o guardarse para no tener que limpiarlos y desinfectarlos. Las alfombras y tapetes no son fáciles de desinfectar. Si los necesita conservar, se deberán lavar en lavadora siguiendo las instrucciones en la etiqueta del artículo y con la configuración de temperatura del agua lo más alta posible, secar con calor o exponerlos a la luz solar. ${ }^{53-66,79-85}$

Por lo general, las áreas al aire libre requieren una limpieza normal de rutina y no es necesario desinfectarlas. Rociar desinfectante en las aceras y parques no es un uso eficiente de los desinfectantes y no se ha comprobado que reduzca el riesgo del público de contraer el COVID-19. No hay evidencia de que el virus que causa el COVID-19 pueda propagarse directamente a seres humanos desde el agua de piscinas, bañeras de hidromasaje o spas, o áreas de juegos acuáticos. El uso, mantenimiento y desinfección adecuados (por ejemplo, con cloro o bromo) debería matar el virus que causa el COVID-19; no obstante, la situación es diferente en áreas al aire libre sin tanta frecuencia de mantenimiento, incluidas áreas de juego u otras instalaciones ubicadas dentro de parques locales, estatales o nacionales. ${ }^{53-66,79-85}$

\section{¿Tiene alguna utilidad el uso de luz ultravioleta y ozono para eliminar el virus COVID-19?}

El uso de luz ultravioleta de longitud de onda corta puede ser de utilidad para la desinfección de las áreas de trabajo aplicada en forma previa al inicio de las actividades. ${ }^{40,41,85,86}$

En el Centro de Electrónica de Energía e lluminación de Estado Sólido de UC Santa Bárbara (SSLEEC), algunos investigadores están desarroIlando LED ultravioleta que tiene la capacidad de descontaminar superficies y potencialmente aire y agua que han estado en contacto con el virus SARS-CoV-2. Lo han empleado en la desinfección de equipos de protección per- sonal, superficies y pisos. La luz ultravioleta con fines de desinfección ya se había utilizado desde hace mucho tiempo, aunque no se ha terminado de demostrar su eficacia en la desinfección SARS-CoV-2. Su uso para estos fines es muy prometedor. Una empresa miembro de SSLEEC, Seoul Semiconductor, reportó una esterilización del 99.9\% del coronavirus (COVID-19) en 30 segundos con sus productos de LED UV. No todas las longitudes de onda UV son iguales; una proviene del sol; la requerida para purificar el aire y el agua y para inactivar microbios sólo puede generarse a través de procesos creados por el hombre. La luz UVC en el rango de $260-285 \mathrm{~nm}$ utilizadas para la desinfección es perjudicial para la piel humana, por lo que su aplicación debe realizarse cuando no hay nadie presente en el momento de la desinfección. La luz UVC germicida convencional (longitud de onda de $254 \mathrm{~nm}$ ) se puede usar para desinfectar espacios desocupados como habitaciones de hospital vacías o vagones de metro vacíos, pero la exposición directa a estas lámparas UV convencionales no es posible en espacios públicos ocupados, ya que esto podría ser un peligro para la salud. Para desinfectar de manera continua y segura las áreas interiores ocupadas, investigadores del Centro Médico Irving de la Universidad de Columbia han estado investigando la luz UVC lejana (longitud de onda de $222 \mathrm{~nm}$ ), la cual no puede penetrar la capa lagrimal del ojo o la capa externa de piel muerta, por lo que no puede alcanzar ni dañar las células vivas del cuerpo. Los investigadores habían demostrado previamente que la luz ultravioleta lejana puede matar de forma segura los virus de la gripe en el aire. La Organización Mundial de la Salud advierte contra el uso de lámparas de desinfección ultravioleta para desinfectar las manos u otras áreas de la piel; incluso una breve exposición a la luz UV-C puede causar quemaduras y lesiones oculares. Existen grandes avances tecnológicos en los dispositivos generadores de luz ultravioleta. Se han empleado lámparas de vapor de mercurio, sistema LED y alineación de varios metales. Llegará el momento cuando se podrá obtener luz más profunda, segura y económica. Aún con sus limitaciones, el uso actual de luz ultravioleta es seguro y económico comparado con los otros medios de desinfección. Más del 99.9\% 
de los coronavirus estacionales presentes en las gotas en el aire murieron cuando se expusieron a una longitud de onda particular de luz ultravioleta cuyo uso es seguro alrededor de los humanos, según descubrió un nuevo estudio en el Centro Médico Irving de la Universidad de Columbia. Podría reducir en gran medida el nivel de virus en el aire en ambientes interiores ocupados por personas. Dicho estudio extiende su investigación a los coronavirus estacionales que son estructuralmente similares al virus SARS-CoV-2 que causa COVID-19..$^{40-86}$ En el curso del estudio, los investigadores utilizaron un dispositivo de nebulización para rociar dos coronavirus comunes. Los aerosoles que contenían coronavirus se hicieron fluir a través del aire frente a una lámpara de UVC lejana. Después de la exposición a la luz UVC lejana, los investigadores hicieron pruebas para ver cuántos de los virus aún estaban vivos. Los investigadores descubrieron que más del $99.9 \%$ del virus expuesto había sido eliminado por una exposición muy baja a la luz ultravioleta lejana. Con base en sus resultados, los investigadores estiman que la exposición continua a la luz ultravioleta lejana en el límite regulatorio actual mataría al 90\% de los virus en el aire en aproximadamente ocho minutos, al 95\% en aproximadamente 11 minutos, al 99\% en aproximadamente 16 minutos y al 99.9\% en unos 25 minutos. La sensibilidad de los coronavirus a la luz ultravioleta lejana sugiere que puede ser factible y seguro usar lámparas aéreas de luz ultravioleta lejana en lugares públicos e interiores ocupados para reducir notablemente el riesgo de transmisión de coronavirus de persona a persona, así como otros virus como la gripe. En un estudio en curso por separado, los investigadores están probando la eficacia de la luz UVC lejana contra el SARS-CoV-2 en el aire. Los datos preliminares sugieren que la luz UVC lejana es efectiva para matar el SARSCoV-2. Dado que el SARS-CoV-2 se transmite en gran medida a través de gotitas y aerosoles que son tosidos y estornudados en el aire, es importante contar con una herramienta que pueda inactivar el virus de manera segura mientras está en el aire, especialmente cuando hay personas cerca. La luz UV lejana es segura en espacios ocupados como hospitales, autobuses, aviones, trenes, estaciones de tren, escuelas, restaurantes, oficinas, teatros, gimnasios y en cualquier lugar donde la gente se reúna en el interior. La luz ultravioleta lejana podría usarse en combinación con otras medidas, como usar mascarillas y lavarse las manos, para limitar la transmisión del SARS-CoV-2 y otros virus. ${ }^{40,41,85,86}$

Es altamente recomendable desechar el equipo de protección personal; si las necesidades obligan a reutilizarlos, podrá ser desinfectado con luz ultravioleta y ozono. ${ }^{40,85-89}$ El ozono ha sido utilizado para la desinfección y para reducir el riesgo de infección por aerosoles que contienen virus como el COVID-19. Es un gas natural compuesto por tres átomos de oxígeno $\left(\mathrm{O}_{3}\right)$, creado por la radiación solar, tiene una función de protección de los efectos nocivos de los rayos UV: es inorgánico, incoloro, seco, con olor fuerte y no agradable, explosivo y soluble en agua pura. Es el oxidante natural más fuerte de la naturaleza, con una vida media corta de 140 min a $0{ }^{\circ} \mathrm{C}$, de 40 minutos a $20^{\circ} \mathrm{C}$ y 25 minutos a $30^{\circ} \mathrm{C}$. Los generadores lo producen a partir de oxígeno puro al pasar por un gradiente de alto voltaje. ${ }^{40,82-90}$ En los organismos forma parte de los radicales libres de oxígeno y participa en la modulación del estrés oxidativo con inducción de citocinas proinflamatorias. Participa en la modulación del sistema inmune, mejora la actividad fagocítica de los neutrófilos y la función de los eritrocitos. ${ }^{89-106}$

La peroxidación que produce el ozono daña la pared celular viral, altera el ciclo reproductivo, inhibe su crecimiento e interrumpe el contacto del virus con la célula. Interviene en la oxidación de glucoproteínas y glucolípidos, bloqueando la función enzimática del virus. El coronavirus tiene una envoltura rica en cisteína, la cual debe permanecer intacta para la actividad viral; la cisteína contiene grupos tiol o sulfhidrilo (-SH), indispensables para la fusión y entrada celular, siendo vulnerables al ozono, con efectos antivirales a largo plazo. La eficacia de la ozonoterapia se debe a la disminución de la carga viral. ${ }^{5,88,89}$ Los virus encapsulados con cubierta lipídica son los más sensibles y el coronavirus es uno de ellos. ${ }^{3,6}$ Una exposición durante 30 minutos a dosis de 0.03 a 10 ppm inactiva los virus contenidos en los aerosoles. Se ha utilizado para inactivar varios virus como el de la hepatitis A, poliovirus, viruela, $\mathrm{VIH}-1$, 
citomegalovirus y Ébola. ${ }^{87-91}$ La concentración para la inactivación viral no es citotóxica, ${ }^{90}$ desinfecta espacios poco accesibles. El beneficio extra de este gas es su pronta transformación en oxígeno molecular sin residuos tóxicos. ${ }^{93-106}$

\section{Para atender un paciente o al público en general, ¿qué equipo de protección se debe usar de acuerdo con el grado de riesgo de contagio?}

Existen varias guías para el uso del equipo de protección personal (EPP) y cuidados preventivos, las recomendaciones las hacen de acuerdo con el riesgo y utilizan cuatro grados (ver infografías): ${ }^{107-109}$

Riesgo bajo. Trabajadores que no tienen contacto con personas conocidas o sospechosas de estar infectadas con SARS-CoV-2. Pueden mantener una distancia mayor a 1.5 metros. Tienen mínimo contacto ocupacional con el público y/o con sus compañeros de trabajo. Recomendaciones: ver infografía.

Riesgo moderado. Son trabajadores de riesgo de exposición media, tienen contacto frecuente $y /$ o cercano, es decir, dentro de 1.5 metros con personas no conocidas que pueden tener la enfermedad; contacto frecuente con viajeros que regresan de lugares donde la pandemia tiene una transmisión generalizada; contacto con el público en general (p. ej: escuelas, trabajo de alta densidad de población, algunos entornos minoristas de gran volumen). Recomendaciones: ver infografía.

Alto riesgo de exposición. Los trabajos de alto riesgo de exposición son aquéllos con alto potencial de exposición a fuentes conocidas o sospechosas de COVID-19. Trabajadores en esta categoría incluyen:

- Personal de asistencia y prestación de atención médica (p. ej: médicos, enfermeras y otro personal del hospital que deben ingresar a las habitaciones), expuestos a pacientes con COVID-19 conocidos o sospechosos. (Nota: cuando dichos trabajadores realizan procedimientos, su nivel de riesgo de exposición se vuelve muy alto).

- Trabajadores de transporte médico (p. ej: ambulancia, operadores) en movimiento de pacientes con COVID-19 conocidos o sospechosos en vehículos cerrados.

- Trabajadores mortuorios involucrados en la preparación (p. ej: para el entierro o cremación) los cuerpos de personas que se sabe que tienen, o sospechosos de tener COVID-19 en el momento de su muerte.

Muy alto riesgo. Los trabajos de riesgo de exposición muy alto son aquéllos con alto potencial de exposición a fuentes conocidas o sospechosas de COVID-19 durante procedimientos médicos, post mortem o de laboratorio específicos. Los trabajadores en esta categoría incluyen:

- Trabajadores de la salud (p. ej: médicos, enfermeras, dentistas, paramédicos, técnicos médicos de emergencia) realizando procedimientos que generan aerosoles ( $p$. ej: intubación, procedimientos de inducción, broncoscopias, algunos procedimientos y exámenes, o recolección invasiva de muestras) en pacientes conocidos o sospechosos de COVID-19.

- El personal sanitario o de laboratorio que recoge o manipula muestras de pacientes con COVID-19 conocidos o sospechosos (p. ej: manipular cultivos de conocidos o sospechosos, pacientes con COVID-19).

- Trabajadores de la morgue que realizan autopsias, que generalmente implican procedimientos generadores de aerosoles, en los cuerpos de personas que se sabe que tienen, o se sospecha que tienen COVID-19 en el momento de su muerte.

\section{DISCUSIÓN}

Existen una gran cantidad de publicaciones respecto a la carga viral y COVID-19, sin embargo, son escasos los trabajos con un nivel de evidencia I o II que permitan emitir cuidados con un alto nivel de recomendación; la mayoría son revisiones simples u opiniones. Los conceptos teóricos de este trabajo consideran las recomendaciones basadas en la mejor evidencia médica. Dichos conceptos deberán cambiar o ajustarse una vez que aparezcan nuevas evidencias, obligando a los lectores a mantenerse actualizados. Utilizamos el principio de precaución, que es un concepto que respalda 
la adopción de medidas protectoras ante las sospechas fundadas que ciertos productos, tecnologías o infecciones crean un riesgo grave para la salud pública. Las recomendaciones que se emitan se harán sin que se cuente todavía con una prueba científica definitiva, y el principio de proporcionalidad terapéutica implica que las medidas preventivas provean mayores beneficios con un riesgo muy bajo o nulo por el uso de estas medidas. Además, dichas recomendaciones preventivas son de bajo costo, accesibles y fáciles de entender y aplicar. ${ }^{111-113}$

En nuestra práctica diaria, los cirujanos plásticos y otros profesionales tenemos que atender al público en general; personas desconocidas para nosotros que pueden ser portadoras del virus, por lo que estamos expuestos a contagiarnos de COVID-19. Todos los pacientes deben considerase positivos de COVID-19 hasta que no se descarte la enfermedad a través de exámenes de laboratorio. La causa más frecuente de contagio es por personas asintomáticas o presintomáticas; al no ser ostensible la enfermedad, se tiende a un mayor descuido con un mayor riesgo. 5,13-22,34-38 Nuestras actividades profesionales debemos hacerlas en una forma responsable y segura; algunas prácticas que no sean escrupulosas aumentarán el riesgo de contagio.

Se ha reconocido que la producción de aerosoles es la principal fuente de contagio en el personal sanitario. Los aerosoles se generan en diferentes procedimientos médicos y quirúrgicos. En las primeras fases de la pandemia, el porcentaje de personal de la salud infectado fue muy elevado. Hoy en día se tienen mejores equipos de protección personal y experiencia, lo que ha permitido adoptar medidas preventivas, logrando disminuir considerablemente los contagios. ${ }^{19-25,33}$

La tasa de ataque del COVID es más alta en espacios cerrados y mal ventilados, donde se convive por mucho tiempo con varias personas sin el debido distanciamiento y sin protección. La mayoría de las veces se ignora que alguna de ellas ya está enferma de COVID; la tasa de contagio es mayor del $80 \%$ y una mortalidad muy alta. A este tipo de propagación se le ha denominado supercontagio. ${ }^{19-22}$ Otra fuente de supercontagio se da con el personal sanitario que tiene que atender pacientes COVID durante largos periodos de tiempo, aspirar sus secreciones respiratorias y no cuentan con el equipo de protección personal adecuado. ${ }^{20-22,33}$ Las circunstancias más comunes para los contagios serían los encuentros cara a cara y las interacciones entre personas durante periodos prolongados. ${ }^{19-22}$

\section{CONCLUSIONES}

Con los datos existentes, concluimos que existen suficientes evidencias que dan soporte a la teoría de que al disminuir la carga viral hay menor probabilidad de contagio y, en caso de adquirir la enfermedad, sea en forma leve o asintomática. Es imperativo reducir la carga viral durante nuestra práctica profesional. Los pilares de los cuidados preventivos que nos ayudarán a disminuir la carga viral son: el uso generalizado de mascarillas, protección ocular, distanciamiento, higiene de las manos y desinfección del ambiente. Aun cuando faltan evidencias, al sospechar o confirmar COVID, estos cuidados deben aplicarse bajo «el principio de precaución», con la finalidad de reducir la transmisión comunitaria del coronavirus. Todas las autoridades sanitarias deberían optar por estas medidas preventivas, ya que no son costosas, son fáciles de aplicar y prometen buenos resultados. ${ }^{42-44,55-85}$ Es importante que la aplicación de esta normatividad tenga un carácter de obligatoriedad y universalidad. iSon normas para todos y todos deben cumplirlas! $!^{39-41}$

\section{REFERENCIAS}

1. Franco AE, Serrano R, Gimeno A, De Juan J, Merino E, Jiménez del Cerro L et al. Estudio de carga viral y antigenemia como valores predictivos de recidiva de infección CMV en el trasplante renal. Nefrología 2007; 27 (2): 202-208.

2. Liu Y, Yan LM, Wan L, Xiang TX, Le A, Liu JM et al. Viral dynamics in mild and severe cases of COVID-19. Lancet Infect Dis 2020; 20 (6): 656-657. doi: 10.1016/S1473-3099(20)30232-2.

3. PCR cuantitativa para la detección de la carga viral. Disponible en: https://www.empireo.es/ enfermedadestransmisionsexual/prueba-de-vih/ vih-cuantitativa/

4. Bai Y, Yao L, Wei $T$, Tian $F$, Jin DY, Chen $L$ et al. Presumed asymptomatic carrier transmission of COVID-19. JAMA 2020; 323 (14): 1406-1407. doi: 10.1001/jama.2020.2565.

5. To KK, Tsang OT, Leung WS, Tam AR, Wu TC et al. Temporal profiles of viral load in posterior 
oropharyngeal saliva samples and serum antibody responses during infection by SARS-CoV-2: an observational cohort study. Lancet Infect Dis 2020; 20 (5): 565-574. doi: 10.1016/S14733099(20)30196-1.

6. Mizumoto K, Kagaya K, Zarebski A, Chowell G. Estimating the asymptomatic proportion of coronavirus disease 2019 (COVID-19) cases on board the Diamond Princess cruise ship, Yokohama, Japan, 2020. Euro Surveill 2020; 25 (10): 2000180. doi: 10.2807/1560-7917.ES.2020.25.10.2000180.

7. Zheng S, Fan J, Yu F, Feng B, Lou B, Zou Q et al. Viral load dynamics and disease severity in patients infected with SARS-CoV-2 in Zhejiang province, China, January-March 2020: retrospective cohort study. BMJ 2020; 369: m1443. doi: 10.1136/bmj.m1443.

8. Long QX, Tang XJ, Shi QL, Li Q, Deng HJ, Yuan J et al. Clinical and immunological assessment of asymptomatic SARS-CoV-2 infections. Nat Med 2020; 26 (8): 1200-1204. doi: 10.1038/s41591020-0965-6.

9. European Centre for Disease Prevention and Control (ECDC). Situation update worldwide [cited 20201 March]. Available from: https://www.ecdc.europa. eu/en/geographical-distribution-2019-ncov-cases.

10. Young BE, Ong SWX, Kalimuddin S, Low JG, Tan SY, Loh J et al. Epidemiologic features and clinical course of patients infected with SARS-CoV-2 in Singapore. JAMA 2020; 323 (15): 1488-1494. doi: 10.1001/ jama.2020.3204.

11. Chang L, Yan Y, Wang L. Coronavirus disease 2019: coronaviruses and blood safety. Transfus Med Rev 2020; 34 (2): 75-80.

12. Huang C, Wang Y, Li X, Ren L, Zhao J, Hu Y et al. Clinical features of patients infected with 2019 novel coronavirus in Wuhan, China. Lancet 2020; 395 (10223): 497-506.

13. Backer JA, Klinkenberg D, Wallinga J. Incubation period of 2019 novel coronavirus (2019-nCoV) infections among travellers from Wuhan, China, 2028 January 2020. Euro Surveill 2020; 25 (5): 2000062. doi: 10.2807/1560-7917.ES.2020.25.5.2000062.

14. Peng L, Liu J, Xu W, Luo Q, Deng K, Lin B et al. 2019 Novel Coronavirus can be detected in urine, blood, anal swabs and oropharyngeal swabs samples. medRxiv 2020. doi: https://doi. org/10.1101/2020.02.21.20026179

15. Nishiura H, Kobayashi T, Miyama T, Suzuki A, Jung $\mathrm{S}$, Hayashi $\mathrm{K}$ et al. Estimation of the asymptomatic ratio of novel coronavirus infections (COVID-19). Int J Infect Dis 2020; 94: 154-155. doi: 10.1016 / j.ijid.2020.03.020.

16. Wu Z, McGoogan J. Characteristics of and important lessons from the coronavirus disease 2019 (COVID-19) outbreak in china summary of a report of 72314 cases from the Chinese Center for Disease Control and Prevention. JAMA 2020; 323 (13):1239-1242. doi: 10.1001/jama.2020.2648.

17. Chen N, Zhou M, Dong X, Qu JM, Gong FY, Han Y et al. Epidemiological and clinical characteristics of 99 cases of 2019 novel coronavirus pneumonia in Wuhan, China: a descriptive study. Lancet 2020; 395: 507-513. doi: 10.1016/s0140-6736(20)30211-7.
18. Luo SH, Liu W, Liu ZJ, Zheng XY, Hong CX, Liu ZR et al. A confirmed asymptomatic carrier of 2019 novel coronavirus. Chin Med J (Engl) 2020; 133 (9): 11231125. doi: 10.1097/CM9.0000000000000798.

19. INFOBAE. ¿Cómo nos contagiamos de COVID-19? Julio 2020. Disponible en: https://www.infobae. com/america/mundo/2020/06/25/como-noscontagiamos-coronavirus-entre-los-expertos-haycada-vez-mas-consensos/.

20. El supercontagio en esta pandemia podría ser una buena noticia. Julio 2020. Disponible en: https://www.nationalgeographic.com.es/ciencia/ supercontagio-esta-pandemia-podria-ser-buenanoticia_15594.

21. Pérez Caballero J. Sobre el uso popular del término "súper propagador" del COVID-19. El Catoblepas 2020; 191: 33.

22. Enfermedad por Coronavirus, COVID 19 Actualización 3 de julio de 2020. Disponible en: https://www.mscbs.gob.es/profesionales/ saludPublica/ccayes/alertasActual/nCov-China/ documentos/ITCoronavirus.pdf.

23. Edwards SP, Kasten S, Nelson C, Elner V, McKean E. Maxillofacial trauma management during COVID-19: multidisciplinary recommendations. Facial Plast Surg Aesthet Med 2020; 22 (3): 157-159. doi: 10.1089 / fpsam.2020.0158.

24. Givi B, Schiff BA, Chinn SB, Clayburgh D, lyer NG, Jalisi $S$ et al. Safety recommendations for evaluation and surgery of the head and neck during the COVID-19 pandemic. JAMA Otolaryngol Head Neck Surg 2020; 146 (6): 579-584. doi: 10.1001/ jamaoto.2020.0780.

25. Wang D, Hu B, Hu C, Zhu F, Liu X, Zhang J et al. Clinical characteristics of 138 hospitalized patients with 2019 novel coronavirus-infected pneumonia in Wuhan, China. JAMA 2020; 323 (11): 1061-1069. doi: 10.1001/jama.2020.1585.

26. Hill DS, O'Neill JK, Powell RJ, Oliver DW. Surgical smoke a health hazard in the operating theatre: a study to quantify exposure and a survey of the use of smoke extractor systems in UK plastic surgery units. J Plast Reconstr Aesthet Surg 2012; 65: 911-916.

27. Ragde SF, Jorgensen RB, Foreland S. Characterization of exposure to ultrafine particles from surgical smoke by use of a fast mobility particle sizer. Ann Occup Hyg 2016; 60 (7): 860-874.

28. Kwak HD, Kim SH, Seo YS, Song KJ. Detecting hepatitis B virus in surgical smoke emitted during laparoscopic surgery. Occupy Environ Med 2016; 73: 857-863.

29. Vourtzoumis P, Alkhamesi N, Elnahas A. Operating during COVID-19: is there a risk of viral transmission from surgical smoke during surgery? Can J Surg 2020; 63 (3): E299-E301.

30. Zhu N, Zhang D, Wang W, Li X, Yang B. A novel coronavirus from patients with pneumonia in China, 2019. N Engl J Med 2020; 382: 727-733. doi: 10.1056 / NEJMoa2001017.

31. Mowbray N, Ansell J, Warren N, Wall P, Torkington J. Is surgical smoke harmful to theater staff? A systematic review. Surg Endosc. 2013; 27 (9): 3100-3107. 
32. Mowbray NG, Ansell J, Horwood J, Cornish J, Rizkallah P, Parker A et al. Safe management of surgical smoke in the age of COVID-19. $\mathrm{Br} J$ Surg 2020; 107 (11): 1406-1407. doi: 10.1002/ bjs. 11679 .

33. Nguyen LH, Drew DA, Graham MS, Joshi AD, Guo CG, Ma W et al. Risk of COVID-19 among front-line health-care workers and the general community: a prospective cohort study. Lancet Public Health. 2020; 5 (9): e475-e483. doi: 10.1016/S24682667(20)30164-X.

34. Stahel PF. How to risk-stratify elective surgery during the COVID-19 pandemic? Patient Saf Surg 2020; 14: 8. doi: 10.1186/s13037-020-00235-9.

35. McKay B, Calfas J, Ansari T. Coronavirus declared pandemic by World Health Organization. Wall St J 2020.

36. Commins J. Surgeon general urges providers to consider stopping all elective surgeries - hospitals push back. Health Leaders 2020.

37. Evans M, Wilde MA. Hospitals push off surgeries to make room for coronavirus patients. Wall St J 2020.

38. Martines J. UPMC shuns health experts' calls to cancel elective surgeries. Pittsburgh Tribune-Review 2020.

39. Barnes M, Sax PE. Challenges of "return to work" in an ongoing pandemic. New Engl J Med 2020; 383: 779-786. doi: 10.1056/NEJMsr2019953.

40. SaifAddin BK, Almogbel AS, Zollner CJ, Wu F, Bonef $\mathrm{B}$, Iza $\mathrm{M}$ et al. AIGaN deep ultraviolet light-emitting diodes grown on SiC substrates. ACS Photonics 2020; 7: 554-561. doi: 10.1021/acsphotonics.9b00600.

41. Ultraviolet LEDs prove effective in eliminating coronavirus from surfaces and, potentially, air and water. Science Daily. 2020. Disponible en: https://www.science daily.com/ releases/2020/04/200414173251

42. Cochrane Iberoamérica. ¿Está justificado el uso generalizado de mascarillas para evitar la transmisión comunitaria del nuevo coronavirus? 19 de abril de 2020. Disponible en: https:// es.cochrane.org/es/\%C2\%BFest\%C3\%A1-justificadoel-uso-generalizado-de-mascarillas-para-evitar-latransmisi\%C3\%B3n-comunitaria-del

43. Coronavirus: mascarillas y evidencias científicas. Urgencias y emergencias. Actualización 22 de junio de 2020. Disponible en: https://www. urgenciasyemergen.com/coronavirus-mascarillas-yevidencia-cientifica/

44. Gandhi M, Beyrer Ch, Goosby E. Masks do more than protect others during COVID-19: reducing the inoculum of SARS-CoV-2 to protect the wearer. J Gen Inter Med 2020. doi: 10.1007/s11606-020-06067-8.

45. Fennelly K. Particle size of infectious aerosols: implications for infection control. Lancet Resp Med 2020. doi: 10.1016/S2213-2600(20)30323-4.

46. Bourouiba L. Turbulent gas clouds and respiratory pathogen emissions: potential implications for reducing transmission of COVID-19. JAMA 2020. doi: 10.1001/jama.2020.4756.

47. Tang JW, Settles GS. Images in clinical medicine. Coughing and aerosols. N Engl J Med 2008; 359: e19.
48. Xie X, Li Y, Chwang AT, Ho PL, Seto WH. How far droplets can move in indoor environments-revisiting the Wells evaporation falling curve. Indoor Air 2007; 17: 211-225.

49. Bahl P, Doolan C, De Silva C, Chughtai AA, Bourouiba L, Macintyre CR. Airborne or droplet precautions for health workers treating COVID-19? J Infect Dis 2020. doi: 10.1093/infdis/jiaa189.

50. Lindsley WG, Noti JD, Blachere FM, Szalajda JV, Beezhold DH. Efficacy of face shields against cough aerosol droplets from a cough simulator. J Occup Environ Hyg 2014; 11: 509-518.

51. Dharmadhikari AS, Mphahlele M, Stoltz A et al. Surgical face masks worn by patients with multidrugresistant tuberculosis: impact on infectivity of air on a hospital ward. Am J Resp Crit Care Med 2012; 185: 1104-1109.

52. Wood ME, Stockwell RE, Johnson GR et al. Face masks and cough etiquette reduce the cough aerosol concentration of Pseudomonas aeruginosa in people with cystic fibrosis. Am J Resp Crit Care Med 2018; 197: 348-355.

53. Prather KA, Wang CC, Schooley RT. Reducing transmission of SARS-CoV-2. Science 2020; 368: 1422-1424.

54. Worldometer. COVID-19 coronavirus pandemic. 2020. Disponible en: https://www.worldometers. info/coronavirus/

55. Guo ZD, Wang ZY, Zhang SF et al. Aerosol and surface distribution of severe acute respiratory syndrome coronavirus 2 in hospital wards, Wuhan, China, 2020. Emerg Infect Dis 2020. doi: 10.3201/ eid2607.200885.

56. Chia PY, Coleman KK, Tan YK, Ong SWX, Gum M, Lau SK et al. Detection of air and surface contamination by SARS-CoV-2 in hospital rooms of infected patients. Nat Commun 2020; 11 (1): 2800. doi: 10.1038/s41467-020-16670-2.

57. Santarpia JL, Rivera DN, Herrera V et al. Transmission potential of SARS-CoV-2 in viral shedding observed at the University of Nebraska Medical Center. medRxiv 2020. doi: 10.1101/2020.03.23.20039446.

58. Cheng V, Wong SC, Chen J et al. Escalating infection control response to the rapidly evolving epidemiology of the coronavirus disease 2019 (COVID-19) due to SARS-CoV-2 in Hong Kong. Infect Control Hosp Epidemiol 2020; 41: 493-498.

59. Wong SCY, Kwong RTS, Wu TC et al. Risk of nosocomial transmission of coronavirus disease 2019: an experience in a general ward setting in Hong Kong. J Hosp Infect 2020; 105: 119-127.

60. Faridi S, Niazi S, Sadeghi K et al. A field indoor air measurement of SARS-CoV-2 in the patient rooms of the largest hospital in Iran. Sci Total Environ 2020; 725: 138401.

61. Ong SWX, Tan YK, Chia PY et al. Air, surface environmental, and personal protective equipment contamination by severe acute respiratory syndrome coronavirus 2 (SARS-CoV-2) from a symptomatic patient. JAMA 2020; 323: 1610-1612.

62. Qualls N, LevittA, Kanade N etal. Community mitigation guidelines to prevent pandemic influenza: United States, 2017. MMWR Recomm Rep 2017; 66: 1-34. 
63. Feng S, Shen C, Xia N, Song W, Fan M, Cowling BJ. Rational use of face masks in the COVID-19 pandemic. Lancet Resp Med 2020; 8: 434-436.

64. Maclntyre R, Chughtai A, Tham CD, Seale H. COVID-19: should cloth masks be used by healthcare workers as a last resort? BMJ 2020. Disponible en: https://blogs.bmj.com/bmj/2020/04/09/covid-19should-cloth-masks-be-used-by-healthcare-workersas-a-last-resort/

65. Jefferson T, Jones M, Al Ansari LA, Bawazeer G, Beller E, Clark J et al. Physical interventions to interrupt or reduce the spread of respiratory viruses. Part 1 Face masks, eye protection and person distancing: systematic review and meta-analysis. medRxiv 2020. doi: https://doi.org/10.1101/2020.03.30.20047217.

66. Chu DK, Akl EA, Duda S, Solo K, Yaacoub S, Schünemann HJ; COVID-19 Systematic Urgent Review Group Effort (SURGE) study authors. Physical distancing, face masks, and eye protection to prevent person-to-person transmission of SARS-CoV-2 and COVID-19: a systematic review and meta-analysis. Lancet 2020; 395 (10242): 1973-1987. doi: 10.1016/S0140-6736(20)31142-9.

67. Howard J, Huang A, Li Z, Tufekci Z, Zdimal V, van der Westhuizen $\mathrm{H}$ et al. Face masks against COVID-19: an evidence review. Preprints 2020; 2020040203 doi: 10.20944/preprints202004.0203.v1.

68. Brainard JS, Jones N, Lake I, Hooper L, Hunter P. Facemasks and similar barriers to prevent respiratory illness such as COVID-19: A rapid systematic review. medRxiv 2020. doi: 10.1101/2020.04.01.20049528.

69. Greenhalgh T, Schmid MB, Czypionka T, Bassler $\mathrm{D}$, Gruer L. Face masks for the public during the covid-19 crisis. Br Med J 2020; 369: m1435. doi: 10.1136/bmj.m1435.

70. WHO Health Emergencies Preparedness and Response Team. Advice on the use of masks in the context of COVID-19. 2020. WHO reference number WHO/2019-nCov/IPC Masks/2020.3.

71. WHO. Non-pharmaceutical public health measures for mitigating the risk and impact of epidemic and pandemic influenza. 2019. ISBN: 978-92-4-151683-9.

72. Recommendation Regarding the Use of Cloth Face Coverings, Especially in Areas of Significant Community-Based Transmission. National Center for Immunization and Respiratory Diseases (NCIRD), Division of Viral Diseases. 2020. Disponible en: https://www.cdc.gov/coronavirus/2019-ncov/prev

73. https://www.fda.gov/medical-devices/personalprotective-equipment-infection-control/n95respirators-surgical-masks-and-face-masks

74. https://www.nelsonlabs.com/testing/bacterial-viralfiltration-efficiency-bfe-vfe

75. http://www.dof.gob.mx/normasOficiales/3926/stps3/ stps3.htm

76. https://multimedia.3m.com/mws/media/1791500O/ comparison-ffp2-kn95-n95-filtering-facepiecerespirator-classes-tb.pdf

77. https://www.cdc.gov/coronavirus/2019-ncov/hcp/ ppe-strategy/index.html

78. https://www.fda.gov/emergency-preparednessand-response/mcm-legal-regulatory-and-policyframework/emergency-use-authorization\#covidppe
79. https://higieneambiental.com/aire-agua-y-legionella/ higiene-de-las-manos-para-prevenir-el-covid-19. 20 de marzo de 2020.

80. https://www.who.int/es/emergencies/diseases/novelcoronavirus-2019/advice-for-public. https://www. paho.org/es/eventos/agua-saneamiento-lavadomanos-entornos-educativos-retos-oportunidadestiempos-covid-19

81. https://www.campusvirtualsp.org/es/curso/covid-19precauciones-basicas-higiene-de-las-manos-2020

82. https://espanol.cdc.gov/coronavirus/2019-ncov/ community/reopen-guidance.html. 7 may 2020

83. https://espanol.cdc.gov/coronavirus/2019-ncov/ community/organizations/cleaning-disinfection.htm

84. https://www.epa.gov/pesticide-registration/list-ndisinfectants-use-against-sars-cov-2

85. https://www.bphc.org/whatwedo/infectious-diseases/ Infectious-Diseases-A-to-Z/Documents/Cleaning\%20 and\%20Disinfecting\%20for\%20COVID\%2019\%20 $-\% 20$ spanish.pdf

86. Buonanno M, Welch D, Shuryak I, Brenner DJ. La luz UVC lejana (222 nm) inactiva de manera eficiente y segura los coronavirus humanos en el aire. Informes Científicos 2020; 10 (1). doi: 10.1038/s41598-02067211-2.

87. Martínez-Sánchez G, Schwartz A, Donna VD. Potential cytoprotective activity of ozone therapy in SARS-CoV-2/COVID-19. Antioxidants (Basel) 2020; 9 (5): 389.

88. Marconcini S, Giammarinaro E, Covani U. The timeliness of ozone in the COVID era. Eur Rev Med Pharmacol Sci 2020; 24 (9):4625-4626.

89. Hernández A, Papadakos PJ, Torres A, González DA, Vives $M$, Ferrando $C$ et al. Two known therapies could be useful as adjuvant therapy in critical patients infected by COVID-19. Rev Esp Anestesiol Reanim 2020; 67 (5): 245-252.

90. Wang J, Shen J, Ye D, Yan X, Zhang Y, Yang W et al. Disinfection technology of hospital wastes and wastewater: Suggestions for disinfection strategy during coronavirus Disease 2019 (COVID-19) pandemic in China. Environ Pollut 2020; 262: 114665.

91. Rubio-Romero JC, Pardo-Ferreira MDC, TorrecillaGarcía JA, Calero-Castro S. Disposable masks: Disinfection and sterilization for reuse, and noncertified manufacturing, in the face of shortages during the COVID-19 pandemic. Saf Sci 2020; 129: 104830.

92. Dev Kumar G, Mishra A, Dunn L, Townsend A, Oguadinma IC, Bright KR et al. Biocides and novel antimicrobial agents for the mitigation of coronaviruses. Front Microbiol 2020; 11: 1351.

93. Smith NL, Wilson AL, Gandhi J, Vatsia S, Khan SA. Ozone therapy: an overview of pharmacodynamics, current research, and clinical utility. Med Gas Res 2017; 7: 212-219.

94. Rowen RJ, Robins H, Carew K, Kamara MM, Jalloh MI et al. Rapid resolution of hemorrhagic fever (Ebola) in Sierra Leone with Ozone therapy. Afr J Infect Dis 2016; 10(1): 49-54.

95. Rowen RJ, Robins HR. A plausible "penny" costing effective treatment for corona virus-Ozone Therapy. J Infect Dis Epidemiol 2020; 6: 113. 
96. Elvis AM, Ekta JS. Ozone therapy: A clinical review. J Nat Sci Biol Med 2011; 2 (1): 66-70.

97. Ricevuti G, Franzini M, Valdenassi L. Oxygen-ozone immunoceutical therapy in COVID-19 outbreak: facts and figures. Ozone Ther 2020; 5: 9014.

98. Semple JL, Moore GWK. High levels of ambient ozone (O3) may impact COVID-19 in high altitude mountain environments. Respir Physiol Neurobiol 2020; 280: 103487. doi: 10.1016/j. resp.2020.103487.

99. Silva EJNL, Prado MC, Soares DN, Hecksher F, Martins JNR, Fidalgo TKS. The effect of ozone therapy in root canal disinfection: a systematic review. Int Endod J 2020; 53 (3): 317-332.

100. Gérard V, Sunnen MD. SARS and ozone therapy: Theoretical considerations [cited in 2003]. Available from: http://www.triroc.com/sunnen/topics/sars.html

101. Tirelli U, Cirrito C, Pavanello M, Piasentin C, Lleshi A, Taibi R. Ozone therapy in 65 patients with fibromyalgia: an effective therapy. Eur Rev Med Pharmacol Sci 2019; 23: 1786-1788.

102. Murray BK, Ohmine S, Tomer DP, Jensen KJ, Johnson FB, Kirsi JJ et al. Virion disruption by ozone-mediated reactive oxygen species. J Virol Methods 2008; 153 (1): 74-77.

103. Alzain S. Effect of chemical, microwave irradiation, steam autoclave, ultraviolet light radiation, ozone and electrolyzed oxidizing water disinfection on properties of impression materials: a systematic review and meta-analysis study. Saudi Dent J 2020; 32 (4): 161-170.

104. Leon OS, Menendez S, Merino N, Castillo R, Sam $\mathrm{S}$, Perez $\mathrm{L}$ et al. Ozone oxidative preconditioning: a protection against cellular damage by free radicals. Mediators Inflamm 1998; 7 (4): 289-294.

105. Zheng Z, Dong M, Hu K. A preliminary evaluation on the efficacy of ozone therapy in the treatment of COVID-19. J Med Virol 2020; 92 (11): 2348-2350.

106. Ricevuti G, Franzini M, Valdenassi L. Oxygen-ozone immunoceutical therapy in COVID-19 outbreak: facts and figures. Ozone Ther 2020; 5: 9014.
107. Guía sobre el uso del equipo de protección personal durante la pandemia COVID-19. Instituto Nacional de Ciencias Médicas y Nutrición Doctor Salvador Zubirán. Actualizado 27 abril 2020. Disponible en: http://www.incmnsz.mx/2020/Guia-equipo-deproteccion-INCMNSZ.pdf

108. Lineamiento técnico de uso y manejo del equipo de protección personal ante la pandemia por COVID-19. Gobierno de México [actualizado 12 de mayo de 2020]. Disponible en: https://coronavirus. gob.mx/wp-content/uploads/2020/05/Lineamiento_ uso manejo EPP

109. Guidance on Preparing Workplace for COVID 19. US department of labor. Disponible en: https://www. osha.gov/Publications/OSHA3990.pdf

110. Casas MML, Portes-Castro MA. Bioética y trasplantes electivos. Principio de proporcionalidad terapéutica. Cir Plast 2010; 20 (1): 43-48.

111. https://es.wikipedia.org/wiki/Principio_de_ precauci\%C3\%B3n

112. Sánchez E. El principio de precaución: implicaciones para la salud Pública. Gac Sanit 2002; 16 (5). Disponible en: http://scielo.isciii.es/scielo.php?script=sci_arttex t\&pid $=$ S0213-91112002000500001

Correspondencia:

Dr. Jesús Cuenca-Pardo

Jerez Núm. 51,

Col. Mixcoac, 03220,

Alcaldía Benito Juárez,

Ciudad de México, México.

E-mail: jcuenca001@gmail.com

Conflicto de intereses: Los autores de este artículo no tienen conflicto de intereses que declarar. 


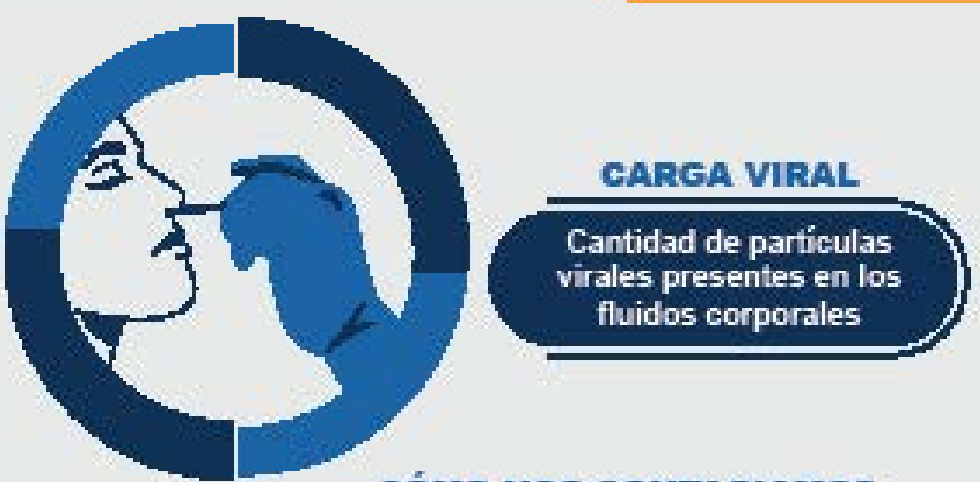

CÓMO NOS CONTAGIAMOS

Las personas asintomáticas o presintomáticas son la principal fuente de contagio. Como la enfermedad es más ostensible en el grupo de pacientes sintomáticos, tienden a ser más cuidadosos y hay menos riesgo.

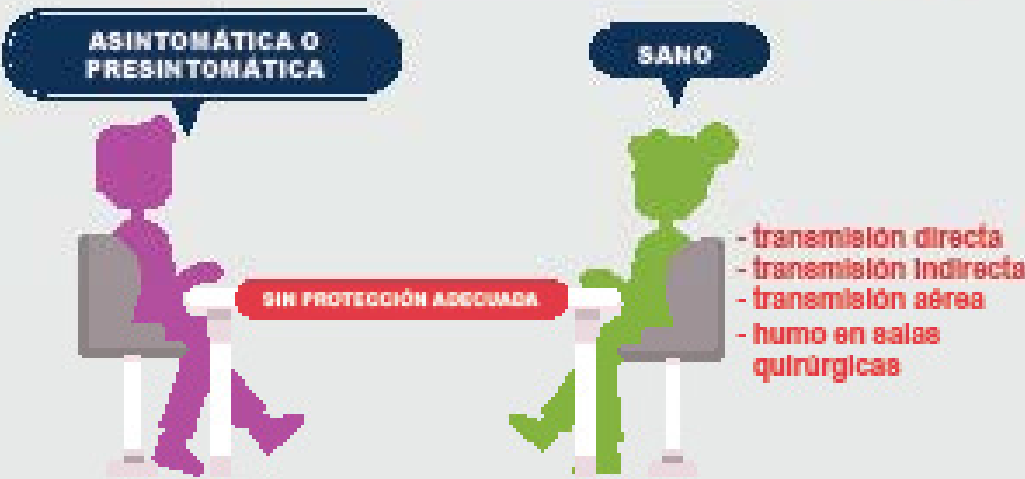

Varios reportes aseguran que es poco común contagiarse de COVID entrando en contacto con una superficie contaminada o durante un encuentro fugaz con una persona enferma.

TRANSMISIÓN AÉREA. Las secreciones respiratorias son expelidas por los pacientes, forman aerosoles con microparticulas < 5 micras que permanecen en el aire por varios minutos; pueden ser aspiradas y depositarse en los alvéolos pulmonares.

Las secreciones respiratorias y otros fluidos corporales son indispensables para la supervivencia y transmisión del virus.

Ha sido considerada como la principal fuente de contagio

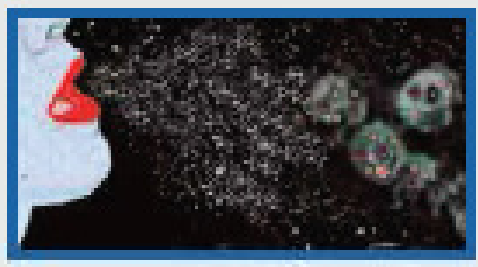
de Covid-19.
UTILIDAD DE CUANTIFICAR LA CARGA VIRAL

- Severidad de la infección

- Pronóstico de la enfermedad - Riesgo de transmitir la infección - Severidad de la enfermedad - Evaluar el tratamiento

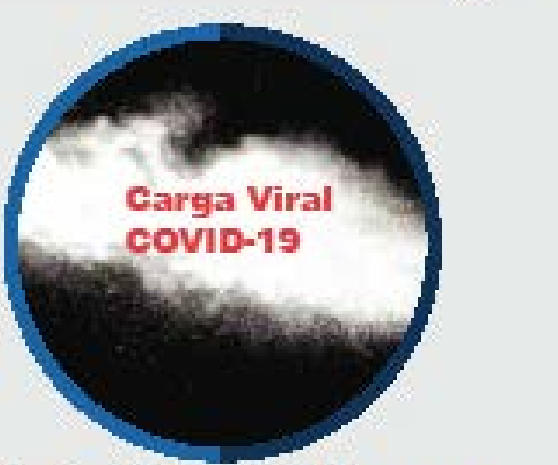

Al disminuir la carga viral logramos:

Evitar el contagio o que la enfermedad sea más leve.

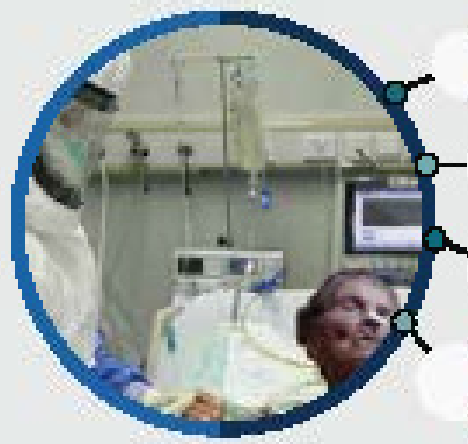

Sangre/plasma

TRANSMISIÓN DIRECTA

CONTACTO CON FLUIDOS EN LOS QUE SE HA ENCONTRADO EL VIRUS DEL SARS-CoV-2.
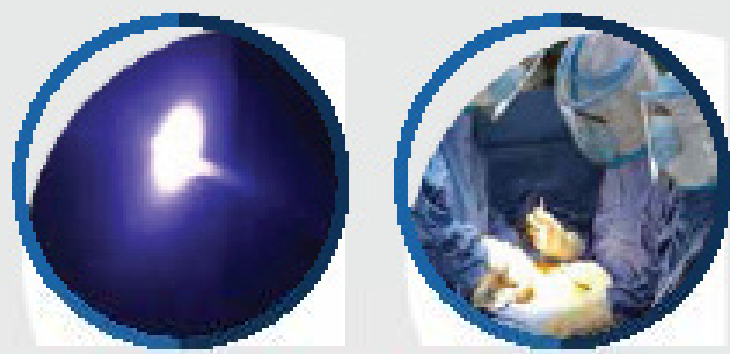

TRANSMISIÓN POR HUMO QUIRÚRGICO

\section{MECANISMO DE FORMACIÓN DE AEROSOLES}

- Las particulas del humo miden de 0.05 a 25 micras.

- Está demostrado que el humo puede contener virus VIH y hepatitis.

- El humo podría contener al SARS-CoV-2.

- No hay estudios que demuestren que el humo sea un medio de transmisión.

- Se debe limitar el uso de dispositivos generadores de energía. 


\section{RECOMENDACIONES \\ DE SEGURIDAD}

\section{CÓMO DISMINUIR LA CARGA VIRAL.}

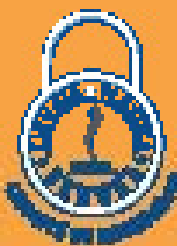

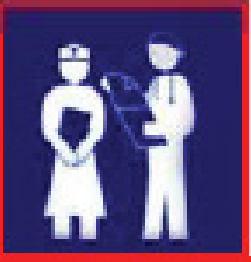
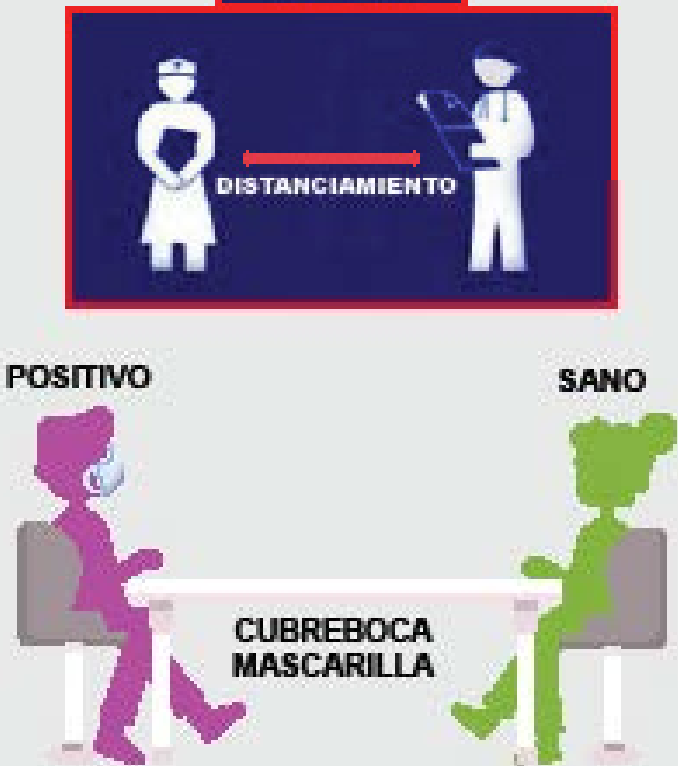

SI LA PERSONA POSITIVA USA MASCARILLA, SE REDUCE $30 \%$ EL RIESGO DE CONTAGIO
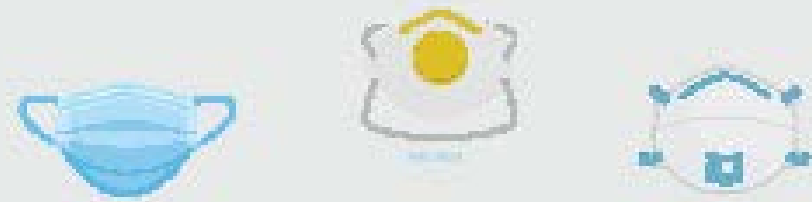

- Mascarillas quirurglcas retienen particulas $>10$ micras

- N95 y almillares filtran el 95\% de microparticulas (5 micras)

- Respiradores con filtros de contencion viral pueden retener particulas « 1 micra

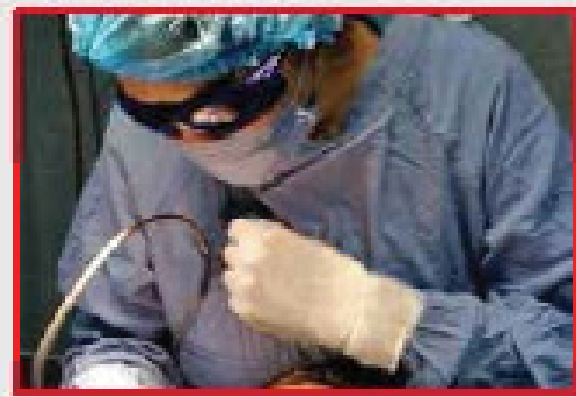

La protección ocular con el uso de goggles o gafas reduce el contagio hasta $10.6 \%$

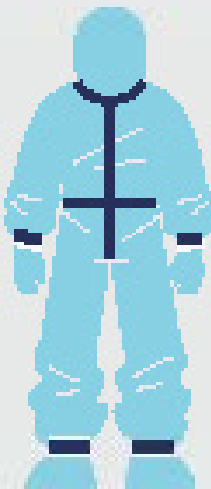

CÓMO DISMINUIR LA CARGA VIRAL

RIESGO DE CONTAGIO

$>$ DE 1 METRO $=10.2 \%$ MENOS CONTAGIO POR CADA 1 METRO EXIRA $=2.02$ VECES MENOS CONTAGIO
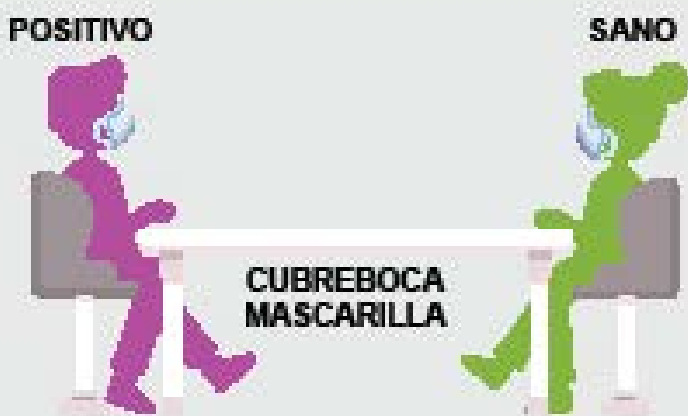

SI LA PERSONA POSITIVA Y LA SANA USAN MASCARIUA, EL RIESGO DE COITAGIO SE REDUCE MÁS DEL $90 \%$

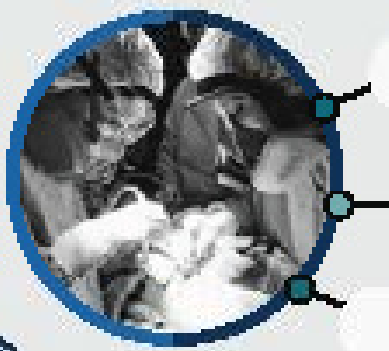

Las mascarillas faciales retienen particulas entre 5 y 10 micras.

Los respiradores con filtros de contención viral pueden retener particulas $<1$ micra.

Los respiradores logran contener hasta 100 veces más particulas de los aerosoles que una mascarilla facial.

Los respiradores filtran hasta el $97 \%$ de particulas de 5 micras y tienen menor efecto en particulas más pequeñas. 
TODOS LOS PACIENTES DEBEN SER CONSIDERADOS COMO SOSPECHOSOS HASTA DESCARTAR LA ENFERMIEDAD.

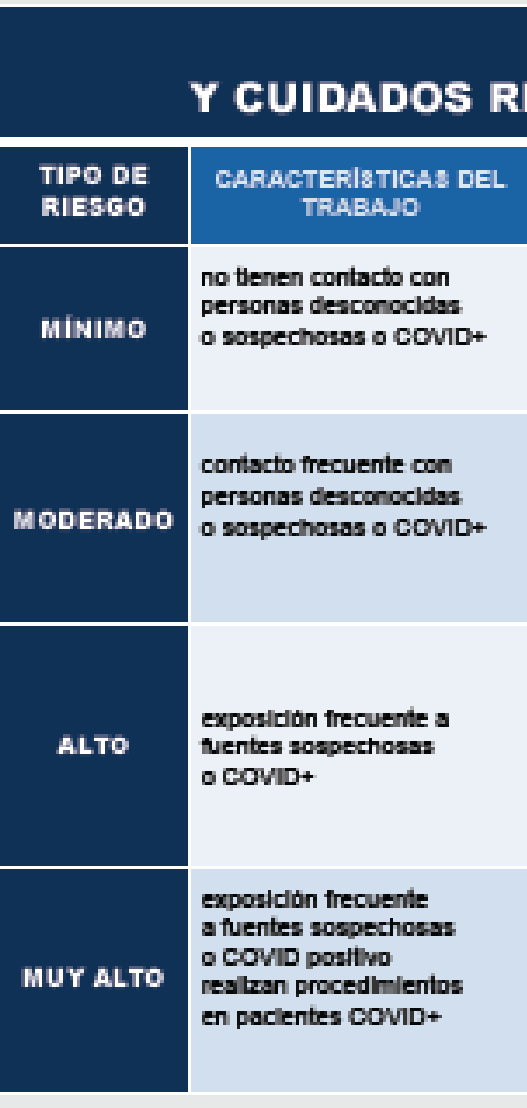

FIGURA 1. EQUIPO DE PROTECCIÓN

COMENDADOS EN LA ATENCIÓN DE UN PACIENTE

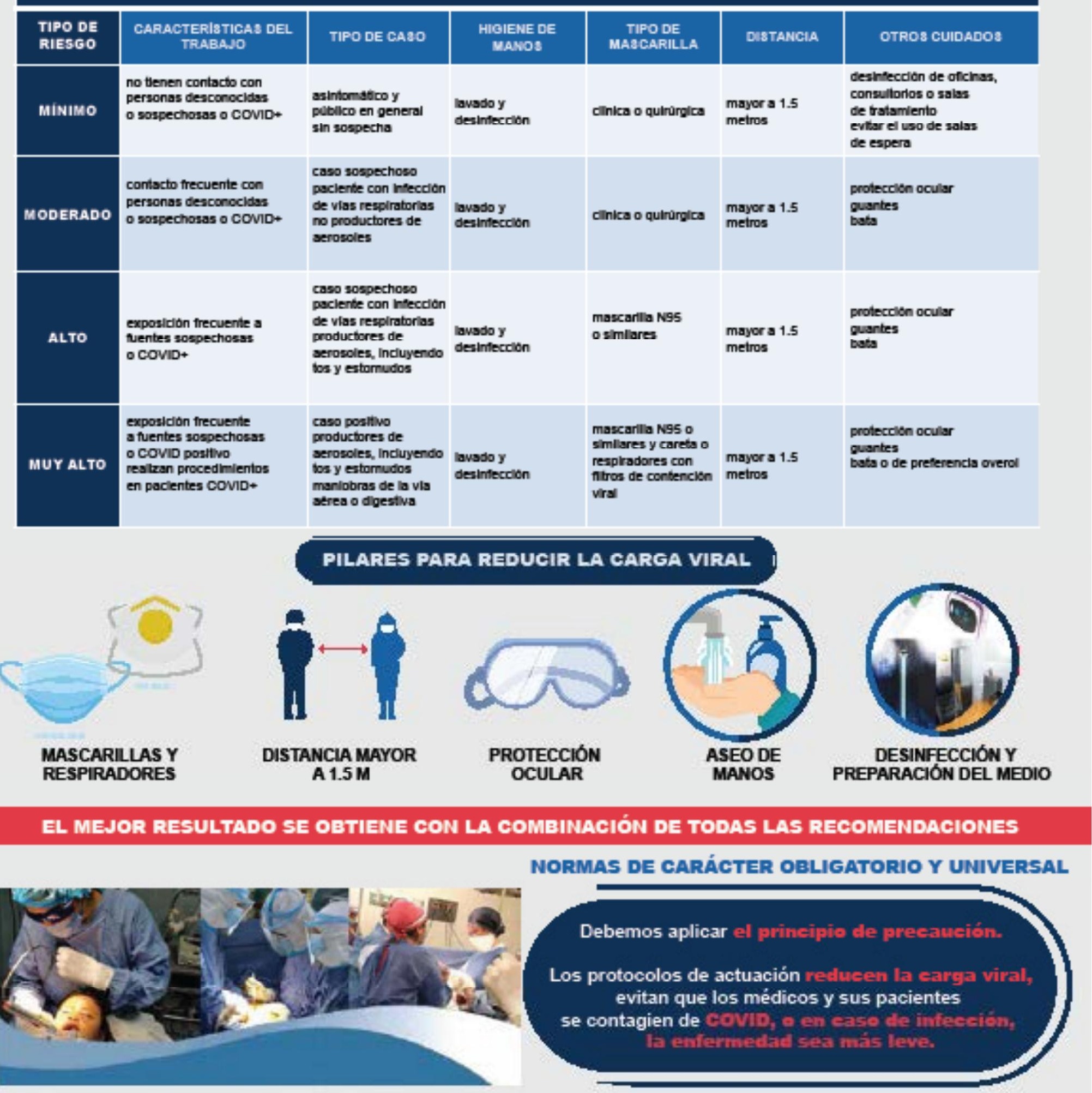

